\title{
So it is, if it seems...
}

\author{
Assim é, se lhe parece...
}

\author{
Asi es, si parece...
}

\author{
1 Instituto Nacional de \\ Câncer, Rio de Janeiro, Brasil. \\ Correspondence \\ L. M. Almeida \\ Instituto Nacional de Câncer \\ Av. Prefeito Dulcídio Cardoso \\ 1100, bloco 2, apto. 707, Rio de \\ Janeiro, RJ 22620-311, Brasil. \\ almeida_liz@hotmail.com
}

Many of these look like the conventional ones... They are known as ENDS (Electronic Nicotine Delivery System). These are electronic devices invented in China, in 2003, with the shape of cigarettes, cigars and pipes, intended to help the smoker quit smoking. They entered the market in 2004, quickly found their way to Europe and, in 2007, reached the Americas 1.

The World Health Organization (WHO) 2 defines ENDS as: “...devices that do not burn or use tobacco leaves but instead vaporize a solution the user then inhales. The constituents of the solution, in addition to nicotine when nicotine is present, are propylene glycol, with or without glycerol and flavoring agents. ENDS solutions and emissions contain other chemicals, some of them considered to be toxicants".

The devices work as nicotine inhalers, but instead of the burning end that releases smoke, they have a small heater. The vapor it produces is similar to the smoke of a conventional cigarette. For this reason, and to be distinguished from the traditional cigarette smoker, ENDS users came to be known as "vapers" 3.

The ENDS were developed to aid smokers to stop using tobacco products, but, they rapidly became an option for smokers who do not want to quit smoking, to former smokers who can smoke a product that is claimed to be harmless
Liz Maria de Almeida ${ }^{1}$

to health, or for those who never smoked for fear of its hazardous effects.

Little is known about the effects of these products on human health. There are a number of studies being carried out, but the long-term effects of their use will only be known in the future. The existence of many types of ENDS, their lack of standardization, and the lack of knowledge about their components prevent the results obtained from a specific brand or type to be extended to others 4 .

It is in this gap of scientific knowledge on the safety and efficacy of the product that manufacturers and vendors are fostering the idea that ENDS is the opposite of a conventional cigarette: "the electronic cigarette is not as harmful as the conventional cigarette". It is "safe for the health of the user and to the people around them", "it gives back the freedom to smoke (or vapor) anywhere, with anyone around, and at any time" 5.

Over the past years, however, hundreds of accidents with ENDS and their accessories came to light, and are related, particularly, to the electric recharging of the device, and to accidental poisoning with nicotine liquids. Therefore, a number of warnings about the products appeared, to contest advertisements that showed the ENDS as being safe for the health - the slogan that accounted for their selling success 1 . 
The ENDS are, therefore, products which, due to lack of regulations, do not have to comply with manufacturing specifications, care with the devices, and warnings about the risks. Currently, there are hundreds of brands worldwide. Liquid nicotine - which is considered a poison - is sold on websites, and the formula to make the liquids can be obtained from a smartphone application 6 .

In fact, the vendors do not know, exactly, what they are selling and the buyer does not know, exactly, what they are buying. All manufacturers state that their products were designed for smokers, and that they are "safe" substitutes for the conventional cigarette. In addition, some claim it is an effective method to treat nicotine addiction. Thus, a major discussion about its regulation came about: either it is a medical product, a method to support nicotine-addiction treatment, or it is a product for consumption, like all other tobacco products. According to the decision a country makes, legislation will be different, as well as the taxes to be collected.

In the first case, for medical use, WHO draws attention to the fact that, to date, there are no studies to prove its effectiveness. In the second case, if it is to substitute conventional cigarette, it must be regulated, standards should be set for its manufacturing, and quality-control rules must be established.

The vendors have advocated the benefits of the ENDS in opposition to the hazards that tobacco products cause to health, which are broadly known by the population. The list of "advantages" includes: “they don't leave cigarette smell in the hair and in clothes", "there is no bad smell in the room", "they don't cause wrinkles", "they don't leave the teeth yellowish", "they don't cause serious illnesses" etc. 7

The use of the ENDS in closed public environments is a sensitive aspect of the business. With the regulation of tobacco-free-environments laws in a number of countries, including Brazil, smokers were forced to leave the closed public environments in order to smoke. In places where climate conditions do not favor smoking outside, that became a huge adversity for smokers. The possibility of allowing smokers to remain in closed environments, therefore, became a major feature of the ENDS.

When they were first launched, with shapes that made them look like ordinary cigarettes, there was complete chaos, people became suspicious and rejected the use of electronic cigarettes in closed environments and airplanes. To make it easier for them to be accepted, the products evolved to new models that did not look like the old electronic cigarettes. The red light that mimicked the burning end of the cigarette was replaced by blue or green colors, or was eliminated. The models evolved to shapes like pens, boxes, cards, etc., of different colors and sizes. To date, there is no scientific evidence about the harmlessness of the fog released by the ENDS in closed public environments. However, advertisement strongly highlighted this feature. A fact that has been emphasized is that, currently, there are no laws preventing vaporizing in specific places or situations.

The major "Achille's heel" of the ENDS is the presence of nicotine in the liquids. How can a product that is sold as being "safe for the health" be an agent to induce and/or maintain physical and psychological addiction? Nicotine is a toxic substance, potentially fatal if ingested in high doses. The users, however, are buying it to prepare their own liquids at home. In addition, this substance even poses the risk of causing lesions if there is skin contact without proper protection. At homes with children or older people with visual and/or cognitive impairment, having nicotine liquids in vials that look like eye drops or nasal spray ones is a risk factor for accidents to occur ${ }^{1}$.

In face of so much controversy, in 2009 the Brazilian Health Surveillance Agency (ANVISA), the health regulatory agency of Brazil, forbade the selling of the ENDS, or similar products and their accessories until evidence is provided of the effectiveness and safety of the product for use. Sales, however do occur, particularly through the Internet and from the black market.

To date, all these issues apparently did not affect this market. In the United Kingdom, one of the major tobacco companies bought the patent of the product inventor for 75 million euros, in 2013. In the United States, one of the three largest tobacco companies announced it had a deal to acquire one of the most popular ENDS brands in the country for 110 million dollars. This was a major shift in their stand, as until recently the tobacco industry only monitored the progression of this business. Apparently, they realized that this new industry, whose market grows exponentially, can be easier to handle and profitable, and may account for their profit margins in the future 8,9 .

In order to reach today's consumers, the product must be presented in a "modern", "politically correct" perspective, with an appealing aspect, and versatile enough to attract all types of users: men, women, youngsters, adults, older people, people of different social classes and tastes, cigarette users, former users and those who never smoked.

The ENDS resort to differentiation and variety, and target the conventional tobacco prod- 
ucts market, but not only this market. The ENDS are electronic, colorful, have applications and exchangeable parts that allow the user to tailor the product according to their preferences.

On the other hand, to encourage the conventional cigarette smoker to use the electronic product with nicotine liquids may potentialize the sales of both products. Differently from what was originally expected, i.e., that the emergence of a new product would lead to the extinction of the previous one, both seems to coexist quite peacefully. Apparently, this is the prevailing perspective among the major companies of the traditional and extremely powerful tobacco industry, who have entered for real in the ENDS market 10 . The key for the business seems to be maintaining the addiction to nicotine! With this, both markets will survive... forever!
1. Bell $\mathrm{K}$, Keane H. Nicotine control: E-cigarettes, smoking and addiction. Int J Drug Policy 2012 23:242-7.

2. World Health Organization. Electronic cigarettes (e-cigarettes) or electronic nicotine delivery systems. http://www.who.int/tobacco/communica tions/statements/eletronic_cigarettes/en/ (accessed on 19/Sep/2014)

3. McQueen A, Tower S, Sumner W. Interviews with "Vapers": implications for future research with electronic cigarettes. Nicotine Tob Res 2011 13:860-7.

4. Bam TS, Bellew W, Berezhnova I, Jackson-Morris A, Jones A, Latif E, et al. Position statement on electronic cigarettes or electronic nicotine delivery systems. Int J Tuberc Lung Dis 2014; 18:5-7.

5. blu eCigs. http://www.blucigs.com/ (accessed on 19/Sep/2014)

6. Como fazer o eLiquido caseiro (DIY). Tutorial in Portuguese. http://www.youtube.com/watch?v= cHr5vZevzIo\&feature=youtube_gdata_player (accessed on 19/Sep/2014).

7. Dicas para iniciantes em cigarros eletrônicos. http://ecigfacil.com/conteudo/O-Que-S\%E3oCigarros-Eletr\%F4nicos.html (accessed on 19/ Sep/2014).

8. Abras Brasil. http://www.abrasnet.com.br/clip ping.php?area $=18 \&$ clipping=37983 (accessed on 19/Sep/2014).

9. Vape ranks: E-cigarette reviews and rankings. http://vaperanks.com/tobacco-giant-altria-acquires-green-smoke-e-cigarettes-for-110-million/ (accessed on 19/Sep/2014).

10. Why electronic cigarettes are about to explode. http://www.forbes.com/sites/karstenstrauss/ 2012/10/24/why-electronic-cigarettes-about-toexplode/ (accessed on 19/Sep/2014).

Submitted on $29 /$ Sep/2014

Approved on 01/Oct/2014 